\title{
Rentabilidade econômica da cultura da alface sob diferentes sistemas de cultivos e tipos de adubos
}

\section{Economic profitability of lettuce cultivation under different cropping systems and types of fertilizers}

\author{
Rodolfo Rodrigo de Almeida Lacerda ${ }^{1 *}$; Caciana Cavalcanti Costa ${ }^{2}$; Jean Telvio Andrade Ferreira ${ }^{3}$; Laiza Gomes de Paiva ${ }^{4}$
}

Resumo: A consorciação de hortaliças aliada ao uso de compostos orgânicos como fonte de nutrientes vem sendo bastante empregado e têm se mostrado eficientes quando assim utilizados. No entanto, para evitar comprometimento do processo produtivo torna-se necessária uma análise econômica. Objetivou-se com o trabalho avaliar a rentabilidade econômica da cultura da alface em sistema consorciado e monocultivo em função de diferentes tipos de adubos. O experimento foi conduzido em condições de campo no Centro de Ciências e Tecnologia Agroalimentar da Universidade Federal de Campina Grande, município de Pombal, Paraíba. O delineamento experimental foi o de blocos casualizados constituídos de três tipos de adubações e dois sistemas de cultivo, em esquema fatorial 3x2 sendo no primeiro fator três adubações: 1= Adubação com Resíduo Animal (Esterco Bovino); 2= Adubação Mineral; 3= Incorporação de vegetação espontânea e no segundo fator dois sistemas de cultivo: $1=$ consórcio e 2 = monocultivo. Nos diferentes sistemas foram mensurados a produtividade, custo operacional total (COT), receita bruta, receita líquida, taxa de retorno e índice de lucratividade, além do uso eficiente da terra (UET). As maiores produtividades foram promovidas pela cultura da alface no tratamento á base de esterco bovino em ambos os sistemas com 16.450,00 e 13.160,00 kg ha ${ }^{-1}$ para o monocultivo e consórcio respectivamente. As melhores rentabilidades pelo Índice de lucratividade também foram observados na cultura da alface quando submetido ao esterco bovino em ambos os sistemas com valores de $88,73 \%$ e $88,28 \%$ para o monocultivo e consórcio respectivamente.

Palavras-chave: Lactura sativum L.; Coriandrum sativum L.; Análise econômica; Produtividade.

\begin{abstract}
The consortium of vegetables combined with the use of organic compounds as a source of nutrients has been widely used and has proved to be efficient when used as such. However, to avoid compromising the productive process, an economic analysis is necessary. The objective of this work was to evaluate the economic profitability of the lettuce crop in a consortium and monoculture system in function of different types of fertilizers. The experiment was conducted under field conditions at the Centro de Ciências e Tecnologia Agroalimentar of the Federal University of Campina Grande, Pombal municipality, Paraíba state. The experimental design was a randomized block consisting of three types of fertilization and two systems of cultivation, in a $3 \times 2$ factorial scheme. The first factor was three fertilizations: $1=$ Fertilization with Animal Residue (Cattle manure); 2 = Mineral Fertilization; 3 = Incorporation of spontaneous vegetation and in the second factor two cropping systems: $1=$ Intercropping and $2=$ monoculture. In the different systems were measured the productivity, total operational cost (TOC), gross revenue, net revenue, rate of return and profitability index, in addition to the efficient use of land (UET). The highest yields were promoted by lettuce cultivation in the treatment of bovine manure in both systems with $16,450.00$ and $13,160.00$ $\mathrm{kg} \mathrm{ha}^{-1}$ for monoculture and Intercropping respectively. The best yields by the Profitability Index were also observed in lettuce culture when submitted to cattle manure in both systems with values of $88.73 \%$ and $88.28 \%$ for monoculture and Intercropping respectively.
\end{abstract}

Key words: Lactura sativum L.; Coriandrum sativum L.; Análise econômica; Produtividade.

Trabalho apresentado no III Simpósio de Ciências e Tecnologia (III SIMTAGRO), realizado entre 02 a 06 de outubro de 2017 no Centro de Ciências e Tecnologia Agroalimentar da Universidade Federal de Campina Grande, Pombal, Paraíba.

*Autor para correspondência

Recebido para publicação em 07/11/2017; aprovado em 23/11/2017

${ }^{1}$ Engenheiro Agrônomo, doutorando do programa de pós-graduação em Agronomia/fitotecnia da Universidade Federal Rural do Semiárido, Mossoró, Rio Grande do Norte, rodolfo-lacerda@ hotmail.com.

${ }^{2}$ Engenheira Agrônoma. Dra. Sc., Professora Adjunto da Unidade Acadêmica de Ciências Agrárias da Universidade Federal de Campina Grande, Pombal, Paraíba. E-mail: costacc@ccta.ufcg.edu.br.

${ }^{3}$ Engenheiro Agrônomo pela Unidade Acadêmica de Ciências Agrárias da Universidade Federal de Campina Grande, Pombal, Paraíba. E-mail: jeantelvio18@hotmail.com.

${ }^{4}$ Engenheira Agrônoma. Mestranda do programa de pós-graduação em Agronomia/fitotecnia da Universidade Federal Rural do Semiárido, Mossoró, Rio Grande do Norte, laizagomes@ outlook.com. 


\section{INTRODUÇÃO}

O consórcio, que é o cultivo de duas ou mais espécies concomitantemente, é uma prática com maior estabilidade de produções visto que se caracterizada pela diversificação em que diferentes espécies de plantas podem ser exploradas ao mesmo tempo e espaço alcançando maior sustentabilidade as atividades agrícolas que contribuem com a manutenção dos sistemas agroecológicos.

O cultivo consorciado vem despertando o interesse dos olericultores não apenas pelo aumento da produção por unidade de área cultivada, mas também por apresenta maior diversidade biológica; maior cobertura do solo e, consequentemente, melhor controle sobre a erosão eólica ou laminar; controle de plantas daninhas; maior eficiência de uso da terra e maior aproveitamento de recursos renováveis, não renováveis utilizados nos cultivos (REZENDE et al., 2005).

Além de promover o melhor controle de doenças e pragas; diminuindo a utilização de insumos como fertilizantes e agrotóxicos proporcionando equilíbrio ecológico (MOTA et al., 2010).

O grande desafio para o sucesso dos sistemas consorciados está na determinação das culturas utilizadas, além da época de instalação e de uma análise econômica para que se possa evitar percas que venham a comprometer o processo produtivo e a renda dos produtores, pois o que se espera no sistema de consórcio é a maximização do uso dos recursos ambientais, biológico e econômico (REZENDE et al., 2006; MONTEZANO, 2006).

Várias pesquisas têm sido realizadas buscando-se obter um maior conhecimento sobre os vários aspectos desse sistema de cultivo. Dentre eles, já ficou comprovada a eficiência agroeconômica de sistemas de cultivo consorciados entre as culturas da alface e tomate (REZENDE et al., 2005); pimentão e repolho, pimentão e alface, pimentão e rúcula, pimentão e rabanete (REZENDE et al., 2006); coentro e rabanete (GRANGEIRO et al., 2008); alface e coentro (SILVA, 2009); alface e rúcula (OLIVEIRA et al., 2010); couve e coentro (RESENDE et al., 2010); coentro e rúcula (MOREIRA, 2011); pimentão e coentro, pimentão e cebolinha (PEREIRA, 2012); alface e rabanete (PAIVA et al., 2014), além de outros consórcios que também tem demonstrado resultados promissores.

Aliado ao consórcio destaca-se o uso de compostos orgânicos como fontes de nutrientes na produção de hortaliças, estas práticas juntas têm se mostrado eficientes quando assim utilizadas (FONTANNÉTI, 2006).

Há poucos estudos referentes à viabilidade agroeconômica dos sistemas consorciados, envolvendo adubação, principalmente a organomineral. Essas informações proporcionarão, aos produtores rurais mais conhecimentos auxiliando na tomada de decisão, com base em dados econômicos.

Assim, há necessidade de aprofundar os estudos de sistematização dos consórcios, analisando a influência da adubação organomineral sobre as características produtivas e econômicas das culturas envolvidas.

Diante do exposto, o objetivo do trabalho foi verificar a viabilidade econômica da cultura da alface em sistemas consorciados, em função de diferentes tipos de adubação organomineral.

\section{MATERIAL E MÉTODOS}

O experimento foi conduzido em condições de campo, no Centro de Ciências e Tecnologia Agroalimentar (CCTA) da Universidade Federal de Campina Grande (UFCG), localizado no município de Pombal, Paraíba, situado geograficamente na latitude $06^{\circ} 46^{\prime} 13^{\prime}$ ' $\mathrm{S}$ e longitude $37^{\circ} 48^{\prime}$ 06" W, com altitude de 184 metros (CAMPOS; QUEIROZ, 2006) no período de 17 de Dezembro de 2015 a 23 de Junho de 2016.

O clima do município, segundo a classificação de Koopen, é do tipo Aw', que representa clima quente e úmido com chuvas de verão/outono, com precipitação média de 800 $\mathrm{mm} \mathrm{ano}^{-1}$. O solo da área experimental foi classificado como Luvissolo Crômico Órtico típico (BRASIL, 1972).

Previamente à semeadura das culturas foi realizada a amostragem do solo na profundidade de $0-20 \mathrm{~cm}$ para fins de caracterização físico-química do solo e da área de cultivo. Realizaram-se amostragens simples para obtenção de uma amostra composta: $\mathrm{pH}(\mathrm{CaCl} 2)=8,00 ; \mathrm{P}=675 \mathrm{mg} \mathrm{dm}^{-3} ; \mathrm{K}^{+}$ $=0,68 \mathrm{cmolc} \mathrm{dm}^{-3} ; \mathrm{Al}^{3+}=0,0 \mathrm{cmolc} \mathrm{dm}{ }^{-3} ; \mathrm{Ca}^{2+}=7,60 \mathrm{cmolc}$ $\mathrm{dm}^{-3} ; \mathrm{Mg}^{2+}=3,80 \mathrm{cmolc} \mathrm{dm}^{-3} ; \mathrm{Na}^{+}=0,08 \mathrm{cmolc} \mathrm{dm}^{-3} ; \mathrm{H}^{+} \mathrm{Al}$ $=0,00 \mathrm{cmolc} \mathrm{dm}^{-3}$; areia, silte e argila corresponderam a 787; 97 e 116 g kg-1, respectivamente.

$\mathrm{O}$ delineamento experimental foi o de blocos casualizados com quatro repetições. Os tratamentos foram, constituídos de tipos de adubações e sistemas de cultivo, em esquema fatorial $3 \times 2$ sendo no primeiro fator três adubações: 1= Adubação com Resíduo Animal (Esterco Bovino); 2= Adubação Mineral; 3= Incorporação de vegetação espontânea e no segundo fator dois sistemas de cultivo: 1-consórcio e 2monocultivo. Os cultivos consorciados, assim como no monocultivo foram estabelecidos pela semeadura direta do coentro (cultura intercalar) nas entrelinhas da alface (cultura principal), que foi instalada pelo transplantio de mudas (Figura 1).

Figura 1. Unidade experimental e disposição das culturas nos tratamentos: A - monocultivo da alface; B - monocultivo do coentro; C - consórcio da alface com o coentro
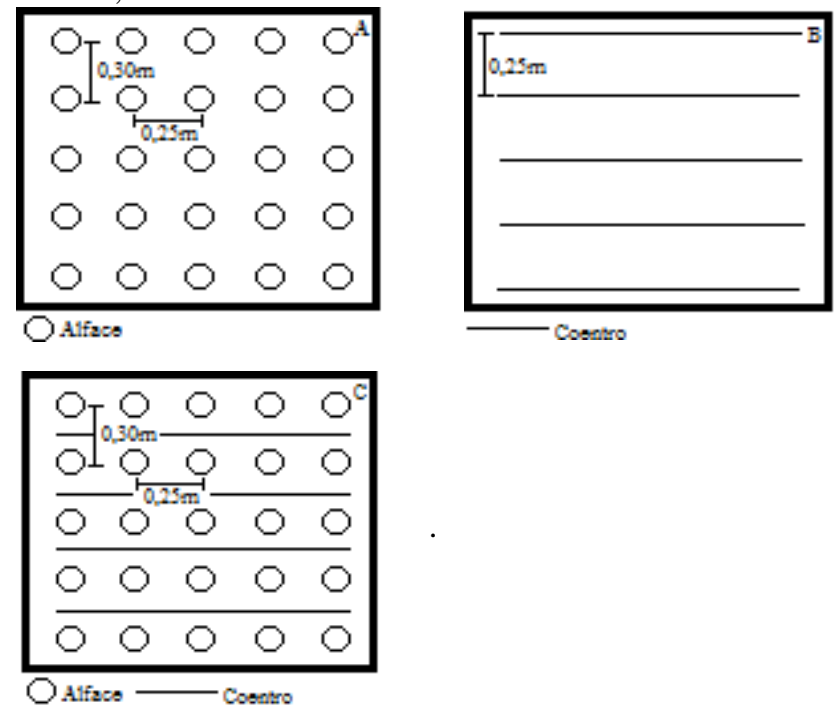

Fonte: Autores (2017)

Cada unidade experimental (parcela) foi de $1,20 \mathrm{~m}$ de comprimento por $1,20 \mathrm{~m}$ de largura e $0,30 \mathrm{~m}$ de altura, o que 
representa $1,44 \mathrm{~m}^{2}$ de área total. Os tratamentos que receberam vegetação espontânea foram preparados 120 dias antes da instalação das culturas e foram capinadas, a vegetação foi incorporada na camada superficial do canteiro de 0 a 15 cm, 30 dias antes da instalação das culturas.

As parcelas que receberam o esterco bovino foram preparadas 15 dias antes da instalação das culturas. Nos tratamentos com a adubação com esterco bovino, as doses foram calculadas com base na recomendação de nitrogênio, segundo de Raij et al. (1997). Para adubação de plantio a dose foi distribuída e incorporada na camada superficial do canteiro de 0 a $15 \mathrm{~cm}$.

As quantidades do esterco foram calculados de acordo com a indicação de Furtini Neto et al. (2001), utilizando-se a equação 1 .

\section{$\mathrm{X}=\mathrm{A} /(\mathrm{B} / 100 . \mathrm{C} / 100 . \mathrm{D} / 100)$}

(Eq. 1)

Em que: $X=$ dose de fertilizante orgânico a ser aplicada, $\mathrm{kg} / \mathrm{ha}^{-1} ; \mathrm{A}=$ dose de $\mathrm{N}$ requerida pela cultura, $\mathrm{kg} \mathrm{ha}^{-1} ; \mathrm{B}=$ teor de matéria seca do fertilizante orgânico, \%; $\mathrm{C}=$ teor de $\mathrm{N}$ na matéria seca do fertilizante orgânico, \%; D = índice de conversão de $\mathrm{N}$ da forma orgânica para a forma mineral, $50 \%$.

Para o controle de plantas daninhas foram efetuadas semanalmente capinas manuais utilizando enxada entre os canteiros e manualmente com o arranquio das plantas.

A irrigação foi feita com base na evapotranspiração da alface, a partir dos dados meteorológicos próximos ao local do experimento, pelo método de Penman-Monteith modificado por Allen et al. (1998) ocorrendo duas vezes por dia. Nesse sentido, nos cultivos em consórcio foi utilizada a lâmina média de irrigação referente às respectivas culturas, mas com o cuidado de não provocar o excesso para uma e a deficiência para outra. A aplicação de água foi pelo método de irrigação localizada por gotejamento, instalada 3 fitas por parcela numa distância de $0,50 \mathrm{~m}$. A colheita das culturas ocorreu quando as mesmas se apresentavam adequadas para o comércio, sendo colhidas de uma única vez.

A estrutura do custo de produção utilizada foi a do custo operacional de produção proposta por Matsunaga et al. (1976) e usada pelo Instituto de Economia Agrícola (IEA) da Secretaria de Agricultura e Abastecimento do Estado de São Paulo.

Para as operações de preparo do solo e aplicação de insumos foram utilizados os coeficientes técnicos baseados em Brancalião (1999). Os demais coeficientes técnicos da pesquisa foram obtidos durante a condução do experimento à medida que se iniciava cada operação.

O custo de mão de obra foi calculado a partir do valor do salário mensal obtido junto ao Sindicato dos Trabalhadores Rurais de Pombal - PB, valores de salários para uma carga horária de 200 horas mensais.

Para o cálculo do custo-hora da máquina (HM) trator, foi levado em consideração a equação 2 .

$$
\mathrm{HM}=\mathrm{s}+\mathrm{g}+\mathrm{r}+\mathrm{m}
$$

Em que: o seguro (s), garagem $(\mathrm{g})$ e reparos $(\mathrm{r})$, foram, respectivamente, $0,75 \%, 1 \%$ e $10 \%$, ao ano, do valor da máquina, considerando 1.000 horas de uso da máquina por ano além dos gastos de manutenção (m), que são cerca de $20 \%$ do total com combustível nas operações, segundo Brancalião (1999).
Para o cálculo do custo-hora de implementos (HI) utilizou-se a equação 3 .

$$
\mathrm{HI}=\mathrm{gr}+\mathrm{r}
$$

Em que: foram considerados os custos com graxa (gr) e reparos (r) 10\%, ao ano, sobre o valor do implemento.

No custo-hora operações (HO) utilizou-se o somatório dos custos com trator, implementos e combustível gasto em cada operação.

Os preços dos insumos e materiais foram obtidos para o mês de junho de 2016 correspondendo ao mês do início do experimento. Os preços foram, em geral, obtidos no banco de dados do Instituto de Economia Agrícola - IEA, enquanto os preços de alguns equipamentos e insumos que não se encontravam disponíveis no banco de dados do IEA, foram obtidos em casas especializadas, na região de Pombal/PB.

A depreciação foi calculada com base no método linear, em que o bem é desvalorizado durante sua vida útil a uma cota constante, conforme a equação 4 .

$$
\mathrm{D}=(\mathrm{Vi}-\mathrm{Vf}) /(\mathrm{N} . \mathrm{H})
$$

Em que: $\mathrm{D}=$ Depreciação ( $\mathrm{R}$ /horas), $\mathrm{Vi}=$ valor inicial (novo), $\mathrm{Vf}=$ valor residual; $\mathrm{N}=$ vida útil (anos) e $\mathrm{H}=$ horas de uso ano. Considerou-se um valor residual para o trator igual a $20 \%$ do valor novo enquanto para os implementos o valor residual foi considerado igual a 0 .

A receita bruta $(\mathrm{RB})$ foi obtida pelo produto entre a produção e o preço da hortaliça sendo que no consórcio foi realizado o cálculo individual para cada cultura e depois o somatório dos valores.

A definição dos preços foi realizada considerando-se os aspectos regionais levantados pela Companhia Nacional de Abastecimento (Conab). O preço considerado no cálculo da receita bruta será coletado conforme a resolução $\mathrm{N}^{\circ} 056$ de 10/07/2013, do GGPAA - Grupo Gestor do Programa de Aquisição de Alimentos (PAA) que elabora para o pagamento dos produtores da agricultura familiar que se enquadra no programa local; é o praticado no mercado atacadista e, portanto, superior ao recebido pelo produtor.

A receita líquida $(R L)$ foi calculada pela diferença entre a receita bruta e o custo operacional total (COT) ambos cálculos estimados para um hectare de área efetiva de canteiro que equivale a $7.500 \mathrm{~m}^{2}$. O cálculo da taxa de retorno (TR) foi obtido pela razão entre a receita bruta e os custos operacionais totais de cada tratamento.

Para a avaliação do índice de lucratividade (IL) utilizouse a razão entre a receita líquida e a bruta, com valores expressos em porcentagem.

Para o cálculo do índice de uso eficiente da terra (UET), em função dos sistemas de cultivo, foi utilizada a equação 5 proposta por Willey (1979).

$$
\mathrm{UET}=(\mathrm{Yab} / \mathrm{Yaa})+(\mathrm{Yba} / \mathrm{Ybb})
$$

Em que: Yab é a produção da cultura "a" em consórcio com a cultura "b"; Yba é a produção da cultura "b" em consórcio com a cultura "a"; Yaa é a produção da cultura "a" em monocultivo e Ybb é a produção da cultura "b" em monocultivo. Para cálculo do UET foram utilizadas as produções das culturas expressas em área $\left(\mathrm{t} \mathrm{ha}^{-1}\right)$, uma vez que existe diferença de estande em função do sistema de cultivo. 


\section{RESULTADOS E DISCUSSÃO}

Observando o rendimento econômico (Tabela 1), verifica-se maior valor de receita bruta no monocultivo da alface com a adubação a base de esterco (T1), atingindo valores que chegam a $\mathrm{R} \$ 83.072,50 \mathrm{ha}^{-1}$. Constata-se também que foi nesse tratamento que houve a obtenção da maior produtividade, além do elevado preço atribuído a alface, fatores esses que levaram ao aumento da receita bruta.

Tabela 1. Produtividade (Prod), preço, receita bruta (RB), custo operacional total (COT) e receita líquida (RL) para a produção de 1 hectare de alface e coentro, em monocultivo e consórcio submetido a diferentes formas de adubação.

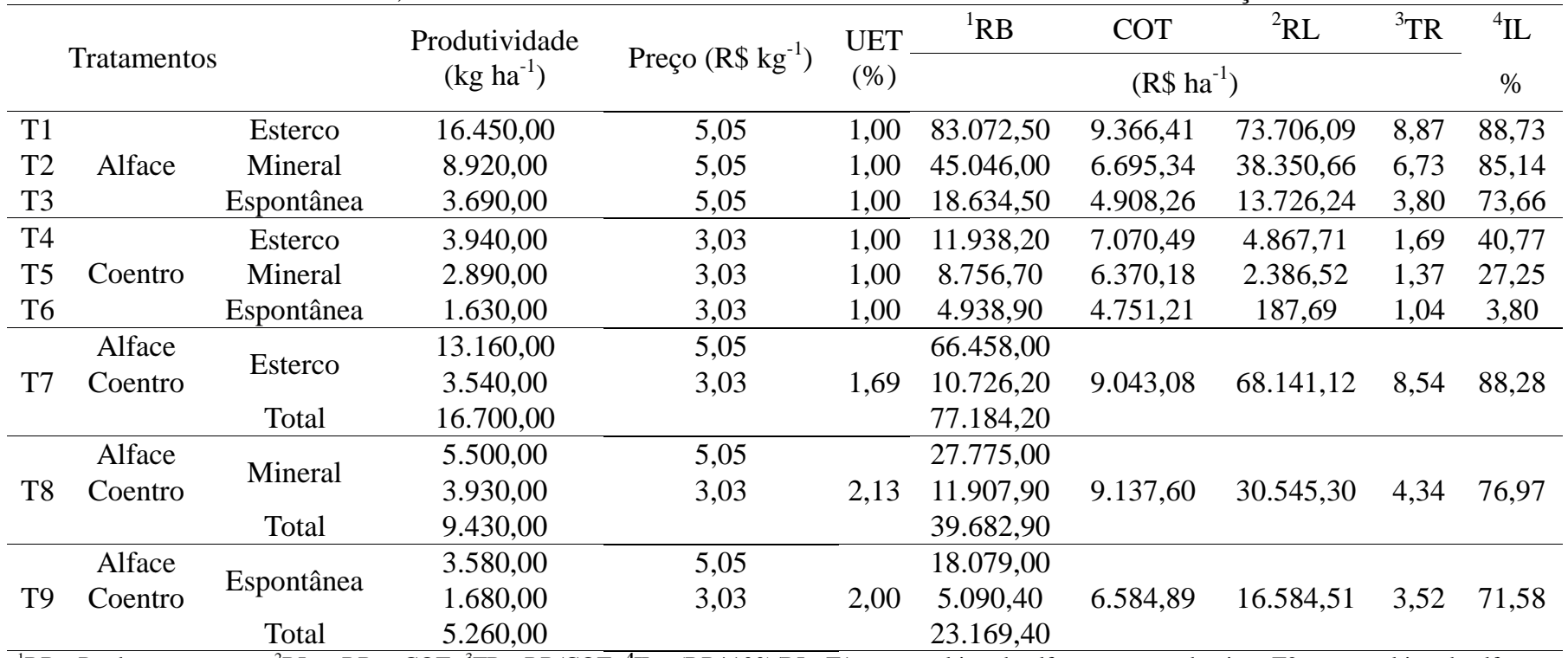

${ }^{1} \mathrm{RB}=$ Produções $\mathrm{x}$ preço; ${ }^{2} \mathrm{RL}=\mathrm{RB}-\mathrm{COT} ;{ }^{3} \mathrm{TR}=\mathrm{RB} / \mathrm{COT} ;{ }^{4} \mathrm{IL}=(\mathrm{RB} * 100) / \mathrm{RL} ; \mathrm{T} 1:$ monocultivo da alface + esterco bovino; $\mathrm{T} 2$ : monocultivo da alface + adubação mineral; T3: monocultivo da alface + adubo verde; T4: monocultivo do coentro + esterco bovino; T5: monocultivo do coentro + adubação mineral; T6: monocultivo do coentro + adubo verde; T7: Consórcio da alface com coentro + esterco bovino; T8: Consórcio da alface com coentro + adubação mineral e T9: Consórcio da alface com coentro + adubo verde.

Nos sistemas consorciados as maiores receitas brutas foram observadas no consórcio da alface com o coentro $\mathrm{R} \$$ $77.184,20 ; \mathrm{R} \$ 39.682,90 ; \mathrm{R} \$ 23.169,40 \mathrm{ha}^{-1}$ quando submetidos a adubações com esterco bovino (T7), adubação mineral (T8) e adubação verde (T9), respectivamente. Oliveira et al.,(2005) utilizando consórcio da alface com coentro observaram uma renda bruta de $\mathrm{R} \$ 26.503,70 \mathrm{~h}^{-1}$, demonstrando assim um resultado satisfatório na utilização de adubações no cultivo consorciado.

Nota-se, no consórcio da alface com coentro na adubação com esterco bovino, valor relativamente próximo ao do monocultivo e quando analisado o Índice de Lucratividade esse comportamento fica mais evidente com respectivos $88,73 \%$ e $88,28 \%$ para monocultivo e consórcio. Ao passo que, o consórcio torna-se mais vantajoso, ao levar em consideração a diversidade de produtos colhidos e consequentemente maior oferta de produtos. Corroborando os trabalhos de Rezende et al. (2004) e Costa et al. (2004) ao afirmarem ter obtido melhores retornos econômicos no bicultivo comparativamente ao monocultivo, sobretudo pela maior receita bruta gerada neste sistema.

A menor receita bruta verificada foi no monocultivo do coentro com adubação verde $\mathrm{R} \$ 4.938,90 \mathrm{ha}^{-1}$, onde é possível observar baixa produtividade ao ser comparado com a alface, além de baixo preço atribuído (Tabela 1).

Para a receita líquida verificou-se maior valor no monocultivo da alface quando adubação com esterco (T1) R\$ 73.706,09 $\mathrm{ha}^{-1}$, acarretando, consequentemente, maior Índice de Lucratividade (IL) com $88,73 \%$.

Nos sistemas consorciados o maior valor de receita líquida e índice de lucratividade ocorreu com a adubação a base de esterco bovino com R \$ 68.141,12 e IL de 88,28 \%, superando as receitas das demais formas de adubações, que obtiveram R\$30.545,3 com IL de 76,97\% e 16.584,51 ha ${ }^{-1}$ com IL 71,58 para adubação mineral e espontâneas respectivamente.

Analisando os custos operacionais totais (COT) dispostos na Tabela 1, constata-se que os custos de implantação de um hectare da alface em monocultivo com diferentes tipos adubações foram estimados em $\mathrm{R} \$ 9.366,41$; $\mathrm{R} \$ 6.695,34$ e $\mathrm{R} \$ 4.908,04 \mathrm{ha}^{-1}$ para as adubações com esterco bovino (T1), adubação mineral (T2) e adubação verde (T3), respectivamente.

Percebe-se que o maior valor de COT foi encontrado no monocultivo da alface adubada com esterco bovino (T1) com $\mathrm{R} \$$ 9.366,41 ha ${ }^{-1}$ (Tabela 1) Em seu trabalho Costa et al.(2008) encontrou um COT de R\$ 3.687,17 no monocultivo da alface lisa a diferença é notória devido a diferença de gastos com insumos. Por outro lado, observa-se que o COT da adubação verde (T3) foi o menor com um valor de $\mathrm{R} \$ 4.908,04 \mathrm{ha}^{-1} \mathrm{o}$ que se explica devido um menor gasto com insumos.

Os custos operacionais totais (COT) de implantação da alface em consórcio com o coentro sob diferentes tipos de adubações foram estimados em R \$9.043,08; R\$ 9.137,60; R\$ 6.472,60 ha-1 para adubação com esterco (T7), adubação mineral (T8) e adubação verde (T9), respectivamente. Rezende (2009) analisando o cultivo consorciado da alface com pimentão encontrou valor bem menor de COT R\$ 3.595,98. O maior COT encontrado foi na adubação mineral (T8), com um acréscimo no tocante as operações especificamente nas adubações de cobertura. O menor valor encontrado na adubação verde uma vez que esta teve um menor custo com insumo. 


\section{CONCLUSÕES}

As maiores produtividades foram promovidas pela cultura da alface no tratamento á base de esterco bovino em ambos os sistemas com 16.450,00 e $13.160,00 \mathrm{~kg} \mathrm{ha}^{-1}$ para o monocultivo e consórcio, respectivamente.

Os maiores custos operacionais totais para produzir um hectare, ocorreram no monocultivo da alface quando adubado com esterco bovino com gastos de $\mathrm{R} \$ 9.366,41$ e no consórcio com uso de adubação mineral com valor de 9.137,60 ha ${ }^{-1}$.

As melhores lucratividades foram observadas na alface quando submetido a adubação com esterco bovino quer seja em monocultivo $(88,73 \%)$ ou em consórcio $(88,28 \%)$.

\section{REFERÊNCIAS}

ALlEN, R. G.; PEREIRA, L. S.; RAES, D; SMITH, M. Crop evapotranspiration: guidelines for computing crop water requirements. Rome: FAO, 300 p (Irrigation and Drainage Paper, 56). 1998.

BRANCALIÃO, S. R. Avaliação econômica dos sistemas de semeadura direta e convencional na sucessão soja/sorgo na região de Ribeirão Preto. 1999. 45f. Monografia (Graduação em Agronomia), Universidade Estadual Paulista, Jaboticabal, 1999.

BRASIL, Ministério da Agricultura, Pecuária e Abastecimento. Levantamento Exploratório: Reconhecimento de Solos do Estado da Paraíba. Rio de Janeiro; Equipe de Pedologia e Fertilidade do Solo (MA), 670p. 1972.

CAMPOS, M. C. C.; QUEIROZ, S. B. Reclassificação dos Perfis Descritos no Levantamento ExploratórioReconhecimento de Solos do Estado da Paraíba. Revista de Biologia e Ciências da Terra, João Pessoa, v. 6, n. 1, p. 45-50. 2006.

FONTANÉTTI, A.; CARVALHO, G. J.; GOMESLA, A.; ALMEIDA, K.; MORAES, S. R. G.; TEIXEIRA, C. M.. Adubação verde na produção orgânica de alface americana e repolho. Horticultura Brasileira 24: 146-150hortic. Bras., v. 24, n. 2, Abr.-jun. 2006.

FURTINI NETO, A. V.; GUILHERME, L. E. G.; GUEDES, G. A. A. Fertilidade do Solo. Lavras: UFLA/FAEPE, 2012. $261 \mathrm{p}$.

GRANGEIRO, L. C.; NEGREIROS, M. Z.; SANTOS, A. P.; COSTA, L. M.; SILVA, A. R. C.; LUCENA, R. R. M. Crescimento e a produtividade de coentro e rabanete em função da época de estabelecimento do consórcio. Revista Ciência e Agrotecnologia, Lavras, v.32, n. 01, p. 55-60. 2008.

MATSUNAGA, M.; Bemelmans, F. P.; TOLEDO, P. E. N. DULlEY, R. D.; OKAWA, H; PEDROSA, I. A. Metodologia de custo de produção utilizada pelo IEA. Agricultura em São Paulo. São Paulo, v. 23, p. 123-139, 1976.

OLIVEIRA, E. Q.; NETO, F. B.; NEGREIROS, M. Z.; BARROS JÚNIOR, A. P.; FREITAS, K. K. C; SILVEIRA, L. M.; LIMA, J. S. S. Produção e valor agroeconômico no consórcio entre cultivares de coentro e de alface. Horticultura Brasileira, Brasília, v.23, n.2, p.285-289. 2005.

MOREIRA, J. N. M. Consorciação de rúcula e coentro adubada com espécie espontânea sucedida pelo cultivo de rabanete. 116 f. Tese (Doutorado em Fitotecnia), Universidade Federal Rural do Semi-Árido (UFERSA), Mossoró-RN. 2011.

MOTA, J. H.; VIEIRA, M. C.; CARDOSO, C. A. L. Alface e jateikaá em cultivo solteiro e consorciado: produção e atividade antioxidante. Revista Ciência e Agrotecnologia, Lavras, v.34, n.03, p.551-557. 2010.

MONTEZANO, E. M.; PEIL, R. M. N. Sistema de consórcio na produção de hortaliças. Revista Brasileira de Agrociência, v.12, n. 02, p.129-132. 2006.

OLIVEIRA, E. Q.; SOUZA, R. J.; CRUZ, M. C. M.; MARQUES, V. B.; FRANÇA, A. C. Produtividade de alface e rúcula, em sistema consorciado, sob adubação orgânica e mineral. Horticultura Brasileira, v.28, n.1, p.36-40. 2010.

PAIVA, L. G.; COSTA, C. C. Desempenho fisiológico de espécies de hortaliças em consórcio, envolvendo variadas arquiteturas e partes produtivas: alface, coentro, rúcula, rabanete e beterraba. In: CONGRESSO INTERNACIONAL DA REALIDADE SEMIÁRIDA, II. Anais... Delmiro Gouveia: UFAL. 2014

PEREIRA, E. D. Estudo da viabilidade agronômica dos policultivos do pimentão com as culturas do coentro, alface e cebolinha. Monografia (Graduação em Agronomia), Universidade Federal de Campina Grande, Pombal, PB. 37f. 2012.

RAIJ, H.; H. CANTARELlA, J. A. QUAGGiO \& A. M. C. Recomendações de adubação e calagem para o Estado de São Paulo. Campinas- São Paulo: Instituto Agronômico. 1997. 285p. (Boletim Técnico).

REZENDE, B. L. A.; CANATO, G. H. D.; CECÍLIO FILHO, A. B. Influência das épocas de cultivo e do estabelecimento do consórcio na produção de tomate e alface consorciados. Revista Ciência e Agrotecnologia, Lavras, v.29, n.01, p.7783. 2005

REZENDE, B. L. A.; CECÍlIO FILHO, A. B.; FELTIM, A. L.; COSTA, C. C.; BARBOSA, J. C. Viabilidade da consorciação de pimentão com repolho, rúcula, alface e rabanete. Horticultura Brasileira, Brasília, v. 25, n. 1, p. 3641, 2006.

RESENDE, A. L. S.; VIANA, A. J. S; OLIVEIRA, R. J.; AGUIAR-MENEZES, E. L.; RIBEIRO, R. L. D.; RICCI, M. S. F.; GUERRA, J. G. M. Consórcio couve-coentro em cultivo orgânico e sua influência nas populações de joaninhas. Horticultura Brasileira, v. 28, n.1, p. 41-46. 2010.

SILVA, A. S. Desempenho das culturas alface, coentro e rúcula em consórcio, no município de Pombal-PB. Monografia de conclusão de Curso (Graduação em Agronomia), Universidade Federal de Campina Grande, Pombal, PB. 28p. 2009. 